\title{
FAKTOR-FAKTOR YANG MEMENGARUHI PENYEBARAN PENYAKIT TUBERKULOSIS (TBC) DI PROVINSI JAWA BARAT
}

\author{
Ni Kadek Ariska Dewi ${ }^{1 \S}$, I Komang Gde Sukarsa ${ }^{2}$, I Gusti Ayu Made Srinadi ${ }^{3}$ \\ ${ }^{1}$ Program Studi Matematika, Fakultas MIPA - Universitas Udayana [Email: ariskadewi31@yahoo.co.id] \\ ${ }^{2}$ Program Studi Matematika, Fakultas MIPA - Universitas Udayana [Email: gedesukarsa@unud.ac.id] \\ ${ }^{3}$ Program Studi Matematika, Fakultas MIPA - Universitas Udayana [Email: srinadi@ unud.ac.id] \\ ${ }^{\S}$ Corresponding Author
}

\begin{abstract}
The highest number of tuberculosis sufferers in Indonesia is in West Java Province. The spread of TB disease depends on a variety of different factors in each region. Due to differences in geographical conditions between regions in West Java, the differences between one variable and different variables give different responses at different locations in each study area. This is called spatial heterogeneity. The method that can be used to overcome the problem of spatial heterogeneity is the Weighted Geographic Regression (GWR) method. The best model of this research is the GWR model using the bisquare adaptive kernel weighting function. The resulting coefficient of determination is $93.79 \%$. Significant variables are the number of households having clean and healthy life behavior (PHBS), the number of male residents, and the number of houses not meeting health requirements.
\end{abstract}

Keywords: Tuberculosis (TB), Geographically Weighted Regression (GWR), Kernel Adaptive Bisquare

\section{PENDAHULUAN}

Tuberkulosis (TBC) merupakan salah satu penyakit menular yang menyebabkan kematian. Mycobacterium tuberculosis merupakan mikrobakteria yang menyebabkan munculnya penyakit TBC ini. TBC dapat menyebar melalui percikan dahak ketika penderita mengalami batuk dan bersin (Suherni \& Maduratna, 2013).

Setiap tahunnya, kasus TBC diseluruh dunia terjadi sebanyak sembilan juta dengan jumlah kematian sebanyak tiga juta jiwa. Terkait jumlah penderita infeksti tuberkulosis, Indonesia menempati urutan ke-3 sedunia hamper sepuluh tahun lamanya (Wulandari, et al., 2016). Tiap tahunnya, Penderita TBC di Indonesia mengalami peningkatan $2-5 \%$ sehingga diperkirakan terdapat 262.000 penderita baru (Aditama, et al., 2013). Data Riskesdas Kemenkes RI (2013), menyatakan lima daerah dengan prevalensi TBC tertinggi di Indonesia yaitu Jawa Barat, Papua, DKI Jakarta, Gorontalo, Banten. Jawa Barat merupakan provinsi pertama dengan jumlah penderita TBC terbanyak di Indonesia dengan angka pravalensi TB $0.7 \%$ (rata-rata nasional 0.4\%) (Yanti, 2016).

Penyebaran penyakit TBC dipengaruhi oleh berbagai faktor yang berbeda di setiap daerahnya. Karena perbedaan kondisi geografis antarwilayah di Jawa Barat menyebabkan terjadinya suatu keadaan dimana satu variabel bebas yang sama memberikan respon yang tidak sama pada lokasi yang berbeda dalam suatu wilayah penelitian. Hal ini disebut dengan heterogenitas spasial.

Salah satu metode penduga faktor-faktor yang memengaruhi penyebaran penyakit TBC di Provinsi Jawa Barat adalah Geographically Weighted Regression (GWR) mengingat adanya heterogenitas spasial. GWR menghasilkan taksiran parameter dari model yang bersifat lokal setiap titik atau lokasi pengamatan, sehingga model yang dihasilkan akan berbeda (Fotheringham, et al., 2002)

Dalam kasus ini berarti pada suatu wilayah yang memiliki perbedaan kondisi antara satu lokasi dengan lokasi lainnya yang ditinjau dari segi geografis, sosial-budaya maupun hal 
lainnya (Munikah, et al., 2014). Berdasarkan hal tersebut, penulis ingin menelaah mengenai faktor-faktor yang memengaruhi penyebaran penyakit TBC di Provinsi Jawa Barat dengan memperhatikan faktor wilayah pada kasus tersebut. Dalam penelitian ini, metode yang digunakan untuk membentuk model penyebaran penyakit TBC di Provinsi Jawa Barat adalah metode GWR. Metode ini meliputi faktor-faktor yang berpengaruh secara signifikan dengan memerhatikan bahwa model hubungan antara variabel terikat dengan variabel bebas adalah linier.

\section{METODE PENELITIAN}

\subsection{Jenis dan Sumber Data}

Dalam penelitian ini data yang digunakan adalah data sekunder tahun 2016. Data mengenai penyebaran penyakit TBC tahun 2016 di Provinisi Jawa Barat terdapat pada Dinas Kesehatan dan Badan Pusat Statistik (BPS). Data tersebut berupa data masingmasing kabupaten/kota di Provinsi Jawa Barat.

\subsection{Variabel Penelitian}

Variabel yang digunakan dalam penelitian ini adalah variabel terikat $(Y)$ dan Variabel bebas $(X)$.

Tabel 1. Variabel Penelitian

\begin{tabular}{|c|c|c|c|}
\hline Kode & Variabel & Definisi & Skala \\
\hline \multicolumn{4}{|l|}{$\begin{array}{l}\text { Variabel } \\
\text { Terikat: }\end{array}$} \\
\hline$Y$ & $\begin{array}{l}\text { Jumlah penderita } \\
\text { TBC }\end{array}$ & $\begin{array}{l}\text { Jumlah penderita TBC pada masing-masing kabupaten di } \\
\text { Provinsi Jawa Barat. }\end{array}$ & Rasio \\
\hline \multicolumn{4}{|l|}{$\begin{array}{l}\text { Variabel } \\
\text { Bebas: }\end{array}$} \\
\hline$X_{1}$ & $\begin{array}{l}\text { Rumah Tangga ber- } \\
\text { PHBS }\end{array}$ & $\begin{array}{l}\text { Jumlah rumah tangga berperilaku hidup bersih dan sehat } \\
\text { pada masing-masing kabupaten di Provinsi Jawa Barat. }\end{array}$ & Rasio \\
\hline$X_{2}$ & Penduduk Miskin & $\begin{array}{l}\text { Jumlah penduduk miskin pada masing-masing kabupaten } \\
\text { di Provinsi Jawa Barat. }\end{array}$ & Rasio \\
\hline$X_{3}$ & Penduduk Laki-laki & $\begin{array}{l}\text { Jumlah penduduk laki-laki pada masing-masing kabupaten } \\
\text { di Provinsi Jawa Barat. }\end{array}$ & Rasio \\
\hline$X_{4}$ & $\begin{array}{l}\text { Rumah tidak } \\
\text { memenuhi syarat } \\
\text { kesehatan }\end{array}$ & $\begin{array}{l}\text { Jumlah rumah tidak memenuhi syarat kesehatan pada } \\
\text { masing-masing kabupaten di Provinsi Jawa Barat. }\end{array}$ & Rasio \\
\hline$u$ & $\begin{array}{l}\text { Koordinat bujur } \\
\text { (longitude) }\end{array}$ & $\begin{array}{l}\text { Koordinat yang dikonversikan kedalam satuan kilometer } \\
\text { yang digunakan untuk menentukan lokasi disebelah barat } \\
\text { atau timur. }\end{array}$ & \\
\hline$v$ & $\begin{array}{l}\text { Koordinat lintang } \\
\text { (latitude) }\end{array}$ & $\begin{array}{l}\text { Koordinat yang dikonversikan kedalam satuan kilometer } \\
\text { yang digunakan untuk menentukan lokasi sebelah utara } \\
\text { atau selatan. }\end{array}$ & \\
\hline
\end{tabular}

\subsection{Teknik Analisis Data}

Adapun teknik analisis data dalam penelitian ini yaitu:

1. Membuat analisis deskriptif untuk melihat penyebaran penyakit $\mathrm{TBC}$ di Provinsi Jawa Barat.

2. Membentuk model regresi linear berganda.

3. Menganalisis model regresi linear berganda dengan tahapan sebagai berikut:

a. Melakukan uji kenormalan dengan menggunakan uji Anderson Darling.

b. Melakukan uji multikolinearitas dengan melihat nilai VIF.
Hipotesis uji:

$H_{0}$ : tidak terdapat multikolinearitas antarvariabel bebas pada model regresi,

$H_{1}$ : terdapat multikolinearitas antarvariabel bebas pada model regresi.

Statistik uji:

$V I F_{k}=\frac{1}{1-R_{k}^{2}}$

Jika nilai VIF $>5$ maka tolak $H_{0}$, yang artinya terdapat multikolinearitas antarvariabel bebas pada model regresi. 
c. Jika terjadi multikolinearitas maka pemilihan variabel dilakukan dengan stepwise regression.

d. Melakukan uji Breusch-Pagan untuk menyelidiki heterogenitas spasial pada data.

Hipotesis uji:

$H_{0}: \quad \sigma_{1}^{2}=\sigma_{2}^{2}=\cdots=\sigma_{n}^{2}=\sigma^{2}$ (tidak terdapat heterogenitas spasial pada data),

$H_{1}$ : minimal ada satu $\sigma_{n}^{2} \neq \sigma^{2}$ (terdapat heterogenitas spasial pada data).

Statistik uji:

$$
B P=\frac{1}{2} f^{T} X\left(X^{T} X\right)^{-1} X^{T} f
$$

$f$ adalah vektor berukuran $n \times 1$ yang elemennya dirumuskan sebagai berikut:

dengan,

$$
f=\frac{e_{i}^{2}}{\hat{\sigma}^{2}}-1
$$

$$
\begin{gathered}
\hat{\sigma}^{2}=\sum_{i=1}^{n} e_{i}^{2} \\
e_{i}^{2}=\sum_{i=1}^{n}\left(Y_{i}-\hat{Y}_{i}\right)^{2}
\end{gathered}
$$

$e_{i}^{2}$ merupakan nilai kuadrat galat, $\hat{\sigma}^{2}$ merupakan varian galat dan $X$ merupakan matriks berukuran $n \times(p+1)$.

Tolak $H_{0} \quad$ jika $\quad B P>X_{p}^{2}$ atau $P_{\text {value }}<\alpha(0,05)$ yang artinya terdapat heterogenitas spasial pada data.

4. Menyusun model GWR dengan langkah sebagai berikut:

a. Menghitung jarak Euclid antar kabupaten ke- $i$ dan ke- $j$ berdasarkan lintang dan bujur.

$d_{i j}=\sqrt{\left(u_{i}-u_{j}\right)^{2}+\left(v_{i}-v_{j}\right)^{2}}$

b. Menentukan nilai bandwidth optimum dengan menggunakan Cross Validation (CV).

$C V=\sum_{i=1}^{n}\left[y_{i}-\hat{y}_{\neq i}(b)\right]^{2}$

c. Menetukan matriks pembobot dengan fungsi kernel fixed bisquare dan adaptive bisquare.

d. Menduga parameter model dengan menggunakan matriks pembobot yang telah diperoleh.

e. Melakukan uji kesesuaian model dengan uji $\mathrm{F}$ untuk mengetahui apakah ada perbedaan antara model regresi linear berganda dengan model GWR.

$$
F_{\text {hitung }}=\frac{\frac{S S E_{\left(H_{0}\right)}}{\left(d f_{1}\right)}}{\frac{S S E_{\left(H_{1}\right)}}{\left(d f_{2}\right)}}
$$

f. Melakukan uji signifikansi parameter dengan uji T (Caraka \& Yasin, 2017).

$$
T_{\text {hitung }}=\frac{\widehat{\beta}_{k}\left(u_{i}, v_{i}\right)}{\operatorname{SE} \widehat{\beta}_{k}\left(u_{i}, v_{i}\right)}
$$

5. Interpretasi hasil.

\section{HASIL DAN PEMBAHASAN}

\subsection{Statistika Deskriptif}

Berikut merupakan statistika deskriptif dari masing-masing variabel:

Tabel 2. Statistika Deskriptif

\begin{tabular}{crrr}
\hline Variabel & Maks. & \multicolumn{1}{c}{ Min. } & Std. Deviasi \\
\hline$Y$ & 8.444 & 365 & 1688,417 \\
\hline$X_{1}$ & 519.724 & 17.615 & 123382,876 \\
\hline$X_{2}$ & 522.934 & 256.770 & 72352,923 \\
\hline$X_{3}$ & 2.856 .530 & 89.910 & 617892,698 \\
\hline$X_{4}$ & 419.426 & 163 & 119986,080 \\
\hline
\end{tabular}

Tabel 2 menunjukkan bahwa provinsi Jawa Barat terdiri dari 27 kabupaten/kota. Jumlah kasus terkonfirmasi penyakit TBC tertinggi di Provinsi Jawa Barat tahun 2016 terdapat di Kabupaten Bogor yaitu sebesar 8.444 orang atau sebesar $14,75 \%$ sedangkan yang terendah terdapat di Kota Banjar yaitu sebesar 365 orang atau sebesar $0,63 \%$.

\subsection{Pemodelan Regresi Linear Berganda}

Dengan menggunakan bantuan software $\mathrm{R}$ i386 3.5.2 diperoleh model regresi linear berganda jumlah penderita penyakit TBC di Provinsi Jawa Barat tahun 2016 sebagai berikut:

$$
\begin{array}{r}
\hat{Y}=883,8+0,003204 X_{1}-0,002348 X_{2} \\
+0,002287 X_{3}-0,003056 X_{4}
\end{array}
$$

\subsection{Uji Normalitas}

Uji kenormalan bertujuan untuk mengetahui sebaran residual berdistribusi normal atau tidak. Uji Anderson-Darling digunakan dalam pengujian normalitas. Dengan menggunakan software $\mathrm{R}$ i386 3.5.2 diperoleh perhitungan $p$ value sebesar 0,3196. Dengan menggunakan taraf signifikan $\alpha_{0,05}$ maka diperoleh $p$-value > a maka terima $H_{0}$. Dengan demikian, residual berdistribusi normal. 


\subsection{Uji Multikolinearitas}

Nilai Variance Inflation Factor (VIF) digunakan untuk mendeterminasi adanya multikolinearitas. Berdasarkan perhitungan menggunakan software R i386 3.5.2 diperoleh hasil sebagai berikut:

Tabel 3. Uji Multikolinearitas

\begin{tabular}{lcccc}
\hline Variabel bebas & $X_{1}$ & $X_{2}$ & $X_{3}$ & $X_{4}$ \\
\hline Nilai VIF & 1,869 & 1,152 & 2,316 & 1,545 \\
\hline
\end{tabular}

Tabel 4. menunjukkan bahwa variabel $X_{1}, X_{2}$, $X_{3}$ dan $X_{4}$ bernilai VIF $<5$. Dengan demikian, tidak ada multikolinearitas antarvariabel bebas pada model regresi.

\subsection{Uji Heterogenitas Spasial}

Untuk mengetahui adanya heterogenitas spasial pada data digunakan uji BreuschPagan.

Tabel 4. Uji Breusch Pagan

\begin{tabular}{cccc}
\hline Uji Breusch- & BP & DF & p-value \\
\cline { 2 - 4 } Pagan & 14,128 & 4 & 0,006896 \\
\hline
\end{tabular}

Berdasarkan Tabel 5 diperoleh $p$-value $(0,006896)<\alpha(0,05)$ yang artinya tolak $H_{0}$. Dengan demikian, terdapat heterogenitas spasial pada data. Karena terdapat heterogenitas spasial pada data maka analisis regresi linear berganda kurang tepat digunakan untuk mengetahui faktor-faktor yang memengaruhi penyebaran penyakit TBC pada masing-masing kabupaten/kota di Provinsi Jawa Barat. Untuk mengatasi masalah terjadinya heterogenitas spasial maka digunakan metode Geographically Weighted Regression (GWR) (Fotheringham, et al., 2002).

\subsection{Pemodelan Geographically Weighted Regression (GWR)}

Tahapan awal dalam membentuk model GWR adalah mengonversi koordinat lintang dan bujur $(u, v)$ setiap kabupaten/kota di Provinsi Jawa Barat menjadi satuan kilometer $(\mathrm{km})$. Koordinat lintang dan bujur untuk seluruh kabupaten/kota di Provinsi Jawa Barat diperoleh dari google earth.

Tahap selanjutnya menentukan matriks pembobot dengan menggunakan fungsi kernel fixed bisquare dan adaptive bisquare. Dalam perhitungan ini diperlukan jarak euclid dan nilai bandwidth yang optimum. Nilai bandwidth didapat dengan menggunakan metode cross validation (CV). Semakin kecil nilai CV maka nilai bandwidth semakin optimum.

Setelah matriks pembobot dengan fungsi kernel fixed bisquare dan adaptive bisquare terbentuk maka akan menghasilkan model untuk setiap kabupaten/kota di Provinsi Jawa Barat.

\subsection{Uji Kesesuaian Model (Goodness of Fit)}

Pada model GWR dengan menggunakan pembobot fixed kernel bisquare diperoleh $F_{\text {hitung }}$ sebesar 0,7216 dengan $F_{\text {tabel }\left(\alpha ; d f_{1} ; d f_{2}\right)}$ sebesar 2,366. Karena $F_{\text {hitung }}<F_{\text {tabel }}$ maka terima $H_{0}$ yang berarti tidak ada perbedaan yang signifikan antara model regresi linear dengan model GWR.

Selanjutnya pada model GWR dengan menggunakan pembobot adaptive bisquare diperoleh $F_{\text {hitung }}$ sebesar 2,577 dengan $F_{\text {tabel }\left(\alpha ; d f_{1} ; d f_{2}\right)}$ sebesar 2,003. Karena $F_{\text {hitung }}>F_{\text {tabel }}$ maka tolak $H_{0}$ yang berarti ada perbedaan yang signifikan antara model regresi linear dengan model GWR.

\subsection{Uji Signifikansi Parameter Model}

Uji signifikansi parameter model dengan selang kepercayaan $\alpha(0,05)$ dan derajat bebas 22 menghasilkan $t_{\text {tabel }}$ sebesar 2,074. Berikut merupakan hasil pengujian signifikansi parameter model GWR di Kabupaten Bogor dengan pembobot fixed bisquare.

Tabel 5. Hasil Uji Signifikansi Parameter Kabupaten Bogor dengan pembobot Fixed Bisquare

\begin{tabular}{ccccc}
\hline & Nilai $\hat{\beta}$ & $\left|t_{\text {hitung }}\right|$ & $t_{\text {tabel }}$ & Keputusan \\
\hline$\hat{\beta}_{1}$ & 0,00187 & 1,844 & 2,074 & Terima $H_{0}$ \\
\hline$\hat{\beta}_{2}$ & 0,00265 & 0,898 & 2,074 & Terima $H_{0}$ \\
\hline$\hat{\beta}_{3}$ & 0,00042 & 5,558 & 2,074 & Tolak $H_{0}$ \\
\hline$\hat{\beta}_{4}$ & 0,00183 & 1,646 & 2,074 & Terima $H_{0}$ \\
\hline
\end{tabular}

Tabel 5 menunjukkan variabel yang signifikan terhadap jumlah penderita TBC di Kabupaten Bogor adalah jumlah penduduk laki-laki $\left(X_{3}\right)$. Hal ini dikarenakan sebagian besar laki-laki mempunyai kebiasaan merokok dan minum alkohol yang dapat menurunkan daya tahan tubuh sehingga dapat terkena penyakit TBC (Manalu, 2010).

Adapun variabel bebas yang berpengaruh signifikan pada masing-masing kabupaten/kota di Provinsi Jawa Barat dapat dikelompokkan menjadi 2 kelompok, seperti tabel 6 : 
Tabel 6. Pengelompokkan Kabupaten/Kota

\begin{tabular}{|c|l|c|}
\hline Kelompok & Kabupaten/kota & $\begin{array}{l}\text { Variabel } \\
\text { yang } \\
\text { signifikan }\end{array}$ \\
\hline 1 & $\begin{array}{l}\text { Kab. Bogor, Kab. } \\
\text { Sukabumi, Kab. } \\
\text { Cianjur, Kab. Bandung, } \\
\text { Kab. Garut, Kab. } \\
\text { Tasikmalaya, Kab. } \\
\text { Ciamis, Kab. Kuningan, }\end{array}$ & \\
& $\begin{array}{l}X_{3} \\
\text { Kab. Cirebon, Kab. } \\
\text { Majalengka,. Kab. }\end{array}$ & \\
& $\begin{array}{l}\text { Sumedang, Kab. } \\
\text { Indramayu, Kab. } \\
\text { Subang, Kab. }\end{array}$ & \\
& $\begin{array}{l}\text { Purwakarta, Kab. } \\
\text { Karawang, Kab. Bekasi, }\end{array}$ & \\
& Kab. Bandung Barat, \\
& Kab. Pangandaran, Kota \\
Bogor, Kota Sukabumi, & \\
& Kota Bandung, Kota \\
& Cirebon, Kota Bekasi, & \\
& Kota Cimahi, Kota \\
Tasikmalaya dan Kota & \\
Banjar. & \\
\hline 2 & Kota Depok & \\
\hline
\end{tabular}

Selanjutnya dilakukan pengujian signifikansi parameter model GWR di Kabupaten Bogor menggunakan pembobot adaptive bisquare.

Tabel 7. Hasil Uji Signifikansi Parameter Kabupaten Bogor dengan pembobot Adaptive Bisquare

\begin{tabular}{ccccc}
\hline & Nilai $\hat{\beta}$ & $\left|t_{\text {hitung }}\right|$ & $t_{\text {tabel }}$ & Keputusan \\
\hline$\hat{\beta}_{1}$ & 0,0010488 & 3,6319 & 2,0034 & Tolak $H_{0}$ \\
\hline$\hat{\beta}_{2}$ & 0,0015751 & 1,5602 & 2,0034 & Terima $H_{0}$ \\
\hline$\hat{\beta}_{3}$ & 0,00024 & 9,6771 & 2,0034 & Tolak $H_{0}$ \\
\hline$\hat{\beta}_{4}$ & 0,001055 & 3,0342 & 2,0034 & Tolak $H_{0}$ \\
\hline
\end{tabular}

Tabel 7 menunjukkan variabel yang signifikan terhadap jumlah penderita TBC di Kabupaten Bogor adalah jumlah rumah tangga ber-PHBS $\left(X_{1}\right)$, jumlah penduduk laki-laki $\left(X_{3}\right)$ dan jumlah rumah tidak memenuhi syarat kesehatan $\left(X_{4}\right)$.

Adapun variabel bebas yang berpengaruh signifikan pada setiap kabupaten/kota di Provinsi Jawa Barat dapat dikelompokkan menjadi 4 kelompok, seperti tabel berikut:
Tabel 8. Pengelompokkan Kabupaten/Kota

\begin{tabular}{|c|c|c|}
\hline Kelompok & Kabupaten/kota & $\begin{array}{c}\text { Variabel } \\
\text { yang } \\
\text { signifikan } \\
\end{array}$ \\
\hline 1 & $\begin{array}{l}\text { Kab. Bandung dan } \\
\text { Kab. Indramayu }\end{array}$ & $\begin{array}{c}X_{3} \text { dan } \\
X_{4}\end{array}$ \\
\hline 2 & $\begin{array}{l}\text { Kab. Cianjur, Kab. } \\
\text { Purwakarta dan Kota } \\
\text { Sukabumi. }\end{array}$ & $X_{1}$ dan $X_{3}$ \\
\hline 3 & $\begin{array}{l}\text { Kab. Bogor, Kab. } \\
\text { Sukabumi, Kab. } \\
\text { Subang, Kab. } \\
\text { Karawang, Kab. } \\
\text { Bekasi, Kota Bogor, } \\
\text { Kota Bekasi dan Kota } \\
\text { Depok. }\end{array}$ & $\begin{array}{c}X_{1}, X_{3} \\
\operatorname{dan} X_{4}\end{array}$ \\
\hline 4 & $\begin{array}{l}\text { Kab. Garut, Kab. } \\
\text { Tasikmalaya, Kab. } \\
\text { Ciamis, Kab. } \\
\text { Kuningan, Kab. } \\
\text { Cirebon, Kab. } \\
\text { Majalengka, Kab. } \\
\text { Sumedang, Kab. } \\
\text { Bandung Barat, Kab. } \\
\text { Pangandaran, Kota } \\
\text { Bandung, Kota } \\
\text { Cirebon, Kota } \\
\text { Cimahi, Kota } \\
\text { Tasikmalaya dan } \\
\text { Kota Banjar. }\end{array}$ & $X_{3}$ \\
\hline
\end{tabular}

Berikut merupakan tabel perbandingan nilai $R^{2}$ dari model regresi linear berganda dan model GWR dengan pembobot fixed bisquare dan adaptive bisquare.

Tabel 9. Perbandingan Nilai $R^{2}$

\begin{tabular}{llc}
\hline Model & $R^{2}$ \\
\hline Regresi Linear Berganda & $85,63 \%$ \\
\hline \multirow{2}{*}{ GWR } & Fixed Bisquare & $87,02 \%$ \\
\cline { 2 - 3 } & Adaptive Bisquare & $93,79 \%$ \\
\hline
\end{tabular}

Tabel 10 menunjukkan bahwa model terbaik yang dapat digunakan untuk memodelkan jumlah penderita TBC di Provinsi Jawa Barat adalah model GWR dengan pembobot adaptive bisquare karena model tersebut memiliki nilai $R^{2}$ terbesar yaitu 93,79\%. Model GWR dengan pembobot adaptive bisquare dapat dilihat pada tabel 4.10. Sebagai contoh Kabupaten Bandung dengan variabel bebas yang berpengaruh secara signifikan diantaranya jumlah penduduk lakilaki $\left(X_{3}\right)$ dan jumlah rumah tidak memenuhi syarat kesehatan $\left(X_{4}\right)$. Estimasi model GWR untuk Kabupaten Bandung yaitu: 


$$
\begin{aligned}
\hat{Y}_{\text {Kab.Bandung }}= & 174,7429+0,002066832 X_{3} \\
& +0,002881171 X_{4}
\end{aligned}
$$

\subsection{Interpretasi Hasil}

Interpretasi dari model diperoleh adalah jika penduduk laki-laki $\left(X_{3}\right)$ dan rumah tidak memenuhi syarat kesehatan $\left(X_{4}\right)$ nilainya adalah 0 maka jumlah penderita TBC di Kabupaten Bandung sebesar 174,7429 orang, apabila penduduk laki-laki $\left(X_{3}\right)$ di Kabupaten Bandung meningkat sebesar satu orang, maka jumlah penderita TBC di Kabupaten Bandung meningkat sebesar 0,002066832 orang dengan variabel lainnya dianggap konstan. Selanjutnya apabila rumah tidak memenuhi syarat kesehatan $\left(X_{4}\right)$ di Kabupaten Bandung meningkat sebesar satu rumah, maka dapat meningkatkan jumlah penderita TBC di Kabupaten Bandung sebesar 0,002881171 orang dengan variabel lainnya dianggap konstan.

\section{KESIMPULAN DAN SARAN}

Berdasarkan perbandingan nilai $R^{2}$ diperoleh model GWR yang pembobotnya adaptive bisquare lebih sesuai digunakan untuk memodelkan jumlah penderita TBC di Provinsi Jawa Barat karena memiliki nilai $R^{2}$ yang lebih besar. Model tersebut mampu menjelaskan jumlah penderita TBC sebesar 93,79\%. Hal ini menunjukkan bahwa GWR merupakan metode yang tepat dikarenakan terdapat heterogenitas spasial pada data.

Berdasarkan variabel bebas yang berpengaruh signifikan pada setiap kabupaten/kota di Provinsi Jawa Barat dengan pembobot adaptive bisquare dikelompokkan menjadi empat kelompok. Variabel yang paling banyak berpengaruh terhadap jumlah penderita TBC pada setiap kabupaten/kota di Provinsi Jawa Barat adalah jumlah penduduk laki-laki $\left(X_{3}\right)$.

Pada penelitian ini masih terdapat variabel yang tidak berpengaruh terhadap model yaitu jumlah penduduk miskin. Diharapkan dalam penelitian selanjutnya dapat menambahkan variabel lain yang berkaitan dengan penyebaran penyakit TBC di Provinsi Jawa Barat.

\section{DAFTAR PUSTAKA}

Aditama, W., Z. \& B. R., 2013. Evaluasi Program Penanggulangan Tuberkulosis Paru di Kabupaten Boyolali. Jurnal Kesehatan Masyarakat Nasional, p. 7.

Caraka, R. E. \& Yasin, H., 2017. Geographically Weighted Regression $(G W R) .1$ st ed. Yogyakarta: Mobius.

Fotheringham, A., Brunsdon, C. \& Charlton, M., 2002. Geographically Weighted Regression: The Analysis of Spatial Varying Relationships. England: Wiley.

Manalu, H. S. P., 2010. Faktor-Faktor yang Mempengaruhi Kejadian TB Paru dan Upaya Penanggulangannya. Jurnal Ekologi Kesehatan, Volume 9, pp. 1340-1346.

Munikah, T., Pramoedyo, H. \& Fitriana, R., 2014. Pemodelan Geographically Weighted Regression dengan Pembobot Fixed Gaussian Kernel pada Data Spasial (Studi Kasus Ketahanan Pangan di Kabupaten Tanah Laut Kalimantan Selatan). Natural B, 2(3), pp. 296-302.

Suherni, N. A. D. \& Maduratna, M., 2013. Analisis Pengelompokan Kecamatan di Kota Surabaya Berdasarkan Faktor Penyebab Terjadinya Penyakit Tuberkulosis. Jurnal Sains dan Seni ITS, p. 2.

Wulandari, A. A., Nurjazuli, N. \& Adi, M. S., 2016. Faktor Risiko dan Potensi Penularan Tuberkulosis Paru di Kabupaten Kendal, Jawa Tengah. Jurnal Kesehatan Lingkungan Indonesia, 14(1), pp. 7-13.

Yanti, N. L. P. E., 2016. Pengendalian Kasus Tuberkulosis Melalui Kelompok Kader Peduli TB (KKP-TB). Jurnal Keperawatan. 